\title{
O DESENVOLVIMENTO DOS ESTADOS UNIDOS: A PARTICIPAÇÃO DO ESTADO NO DESENVOLVIMENTO ECONÔMICO E TECNOLÓGICO
}

\author{
Beatriz Ramos Duarte Baeta Neves \\ Graduanda em Relações Econômicas Internacionais - UFMG \\ E-mail: beatrizramosneves@gmail.com \\ Odilon Francisco Gomide Amaral \\ Graduando em Relações Econômicas Internacionais - UFMG \\ odilonufmg@yahoo.com
}

\section{RESUMO}

A maioria das teorias do desenvolvimento e dos relatos dos historiadores econômicos deixa evidente que Estado e economia andam juntos quando o tema é progresso econômico e tecnológico. Lançar o olhar para os Estados Unidos, um país que se considera a personificação da Liberdade, sobretudo econômica, e desvendar o mito do livre comércio como caminho para - desenvolvimento são passos reveladores para compreender as economias que não conseguiram avançar aplicando a fórmula "mágica" do neoliberalismo. Apesar de ter em vista essa desmitificação, não há a intenção neste trabalho de ditar qual o melhor caminho para o catch up das economias retardatárias e, sim, por meio de uma breve revisão bibliográfica, observar quais foram, de fato, os artifícios utilizados pelos EUA para se desenvolverem.

Palavras-chave: Desenvolvimento; Estados Unidos; Neoliberalismo.

\section{ABSTRACT}

Most development theories and reports by economic historians make it clear that the state and the economy go together when it comes to economic and technological progress. Looking at the United States, a country that considers itself the personification of freedom, above all economic, 


\section{Neves \& Amaral}

and unraveling the myth of free trade as a path to development are revealing steps to understand the economies that have failed to advance by applying the "magic" formula of neoliberalism. Despite having this demystification in mind, there is no intention in this work to dictate the best way to catch up the laggard economies, but, through a brief bibliographic review, to observe which were, in fact, the devices used by USA to develop.

Keywords: Development; United States; Neoliberalism.

\section{INTRODUÇÃO}

Com base na grande maioria das teorias do desenvolvimento e dos relatos dos historiadores econômicos, percebe-se que Estado e economia andam juntos quando o tema é progresso econômico e tecnológico. Contudo, essa percepção é desafiada quando os predizeres neoliberais ditm que o caminho para o desenvolvimento se dá de forma contrária ao que a história mostra. Isto é, quando prega o livre comércio e o Estado mínimo, por exemplo. Chang (2002) demonstra com base em uma análise histórico-comparativa que o desenvolvimento pelas vias neoliberais não passa de um mero mito propagado pelas nações já desenvolvidas.

A "sugestão" neoliberal é que cada nação invista naquilo que melhor produz, abra suas fronteiras para o mercado internacional e torça para que o ambiente competitivo do mercado traga o desenvolvimento. Mas, como será abordado neste trabalho, as nações que se desenvolveram com maior maestria não se escusaram de fazer do Estado e do protecionismo seus grandes aliados. Assim, foi criado um ambiente doméstico propício para a inovação, pesquisa e desenvolvimento de novos produtos e serviços, com a garantia de que o capital privado não estaria sendo colocado em risco. A abertura comercial apenas teve vez nesses países quando já haviam consolidado sua liderança em determinado eixo tecnológico, garantido competitividade frente ao mercado internacional. E, ainda sob essas condições, esses países viveram momentos de ida e volta, ao abrirem e fecharem suas fronteiras, ao perceberem que a exposição ao mercado internacional ameaçava sua classe burguesa doméstica, assim como sua liderança tecnológica (CHANG, 2002).

Não apenas o fator econômico, mas o neoliberalismo também inspira valores que fazem dele algo como que intocável. Ao ditar sobre a liberdade individual e econômica e associá-las à dignidade humana (HARVEY, 2008), essa corrente de pensamento se torna sedutora. Aspecto que talvez justifique a insistência e sobrevivência das políticas neoliberais 
apesar das demonstrações de seu fracasso ao promover o desenvolvimento para as economias retardatárias.

Este trabalho lança o olhar para um país que se considera a personificação da liberdade, sobretudo econômica, e da prosperidade, e se propõe a ressaltar o aspecto mitológico do livre comércio como caminho para o desenvolvimento. A partir desse olhar, tornase mais fácil compreender as economias que não conseguiram avançar aplicando a fórmula "mágica" do neoliberalismo. Apesar de ter em vista essa desmistificação, não há a intenção de ditar qual o melhor caminho para o catch-up das economias retardatárias, tendo em vista que as circunstâncias em que os EUA se desenvolveram são muito diversas das observadas na atualidade.

Em formato de uma breve revisão bibliográfica, explora-se sobre o desenvolvimento dos Estados Unidos como potência global, tendo como objetivo principal observar a participação do Estado nesse processo e destacar pontos de vistas acadêmicos que discorrem se, como ocorrido em outros processos de acumulação de capital em outras nações, houve maiores intervenções estatais, tais como investimentos de iniciativa pública, implementação de tarifas, restrições no âmbito do comércio exterior e mitigação ou manutenção da baixa distribuição de renda. Espera-se mostrar que, para muitos autores, não há desenvolvimento sem a atuação estatal, afastando a ideia, às vezes chamada de lenda -como por Chang (2002)neoliberal de desenvolvimento e ainda salientar que "o capitalismo só triunfa quando se identifica com o estado, quando é o Estado" (BRAUDEL, 1977, p. 64-5 apud ARRIGHI, 1996).

\section{A ESTREIA NEOLIBERAL COMO PARADIGMA}

Os tempos atuais - muito marcados pelos debates econômicos e políticos- são um convite para confrontar a ideologia dominante, sobretudo em contexto brasileiro, sobre desenvolvimento e crescimento econômico. O ano de 2013 foi marcado por inúmeras manifestações populares, inflamadas pela insatisfação com o governo e suas políticas, além de acusar o Estado de "ser muito grande". Na sequência, em 2015 foi promulgada a "PEC do Teto de Gastos Públicos" (Emenda Constitucional 95) ${ }^{1}$ que limita por 20 anos os gastos públicos, sendo corrigidos apenas pela inflação. A síntese deste cenário é expressada pelo governo atual (presidido por Jair Bolsonaro) que tem como metas acompanhar o governo dos EUA (de Donald

1 https://www12.senado.leg.br/noticias/materias/2016/12/15/promulgada-emenda-constitucional-do-teto-degasto

s/

Revista Multiface | Belo Horizonte | v. 9, n. 1, p. 37-58, 2021 
Trump) no que tange a cultura, economia e política. As premissas que justificam tal pretensão é que os EUA seriam um país exemplar, livre comercialmente, e que seu "modelo de desenvolvimento", aplicado ao Brasil, garantiria o retorno do crescimento da economia ${ }^{2}$.

Harvey (2008) expressa que nenhuma corrente ideológica se instaura à parte de um aparato conceitual que mobilize sensações, instintos, valores e desejos. O neoliberalismo emerge com ideais de dignidade humana e liberdade individual como centro de suas preocupações. Tais valores, que são caros a todos os indivíduos, estariam sujeitos a ameaças diante das ditaduras comunistas e fascistas ou qualquer outro nome que se dê a uma intervenção estatal (HARVEY, 2008). Para os preciosistas, até mesmo uma intervenção que busca a correção de alguma falha de mercado seria inadequada, pois daria indícios de um governo com tendências ameaçadoras.

Porém, os EUA não são o melhor espelho para a propagação da liberdade como eles se pretendiam fazer. Pela liberdade, a nação do Tio Sam promoveu guerras, "libertando" países, como no caso do Iraque, além de implementar ditaduras, às surdinas, na América Latina. O espelho que o atual Ministro da Economia do Brasil pretende seguir só foi de fato implantando nos Estados Unidos nos anos 1980 - apenas após ter passado por uma experiência de laboratório: O Chile do Pinochet (HARVEY. 2008).

A convite de Pinochet, os Chicago Boys compuseram o aparato econômico da ditadura chilena. Esse grupo de economistas era composto por chilenos que, por meio de uma bolsa de estudos, foram estudar na Chicago's School of Economics (ALMEIDA, 2020). No contexto da Guerra Fria, essa cessão de bolsas de estudos compunha um plano para neutralizar tendências esquerdistas na América Latina (HARVEY, 2008). Em Chicago, os estudantes chilenos se tornaram discípulos de Milton Friedman e mais tarde, com o golpe de 11 de setembro no Chile, os Chicago Boys inauguram o neoliberalismo na América Latina (HARVEY, 2008).

O primeiro ato dos economistas foi a negociação de um empréstimo junto ao $\mathrm{FMl}$ e a reestruturação econômica do país. As nacionalizações foram revertidas, os recursos naturais foram liberados para exploração privada não regulamentada, a seguridade social foi privatizada, o comércio livre foi facilitado, dentre várias outras medidas "tradicionais" para uma experiência neoliberal delux. A recuperação da economia chilena graças à dádiva neoliberal não perdurou muito, pois logo veio a crise da dívida, em 1982 (HARVEY, 2008).

Estes poucos anos serviram de subsídio para a posterior implantação do sistema nos EUA e na Grã Bretanha. A diferença, no entanto, é que estes países já se encontravam em

2 https://exame.com/economia/economia-pode-crescer-25-apesar-de-crise-do-coronavirus-diz-guedes/

40 Revista Multiface | Belo Horizonte | v. 9, n. 1, p. 37-58, 2021 
patamar industrial-tecnológico muito distantes do patamar chileno da década de 1970 e não tinham como objetivo utilizar do sistema de livre comércio para desenvolver suas economias, isto é, torná-las industriais. Em verdade, tanto a Grã Bretanha quanto os Estados Unidos lançaram mão de estratégias opostas aos predizeres neoliberais para se desenvolverem (CHANG, 2002). Neste contexto, o clamor pelo neoliberalismo apenas se faz benéfico para os países desenvolvidos, enquanto que deixa os demais países acuados e com suas economias ameaçadas.

Para um país que não possui uma estrutura industrial bem estabelecida, abrir suas fronteiras para os bens industrializados de outras nações sem qualquer proteção aos produtos nacionais representa um obstáculo para o seu desenvolvimento interno. Isso porque, dada a vantagem tecnológica dos bens importados, seus preços serão mais competitivos e de melhor qualidade, colocando em escanteio os bens domésticos. Este processo acarretará na saída da produção doméstica naquele setor. Logo, ela será direcionada para setores de menor complexidade, como produção de bens primários.

\section{ESTADO E DESENVOLVIMENTO}

Apesar do discurso, não muito incomum, de que o Estado deveria ser administrado como uma empresa, os objetivos de um e outro são muito distintos: enquanto uma empresa busca $\circ$ lucro e sua sobrevivência, o Estado busca, em suma, o bem-estar da sua população. Em conjunto a esse discurso, é também declarado que "[a] atividade comercial é aceita como força inovadora enquanto o Estado é projetado como uma força paralisante - necessária para o "básico", porém muito grande e pesada para ser o mecanismo dinâmico." (MAZZUCATO, 2011, p. 32), o que tem incentivado um desmonte progressivo do Estado. Em um bom "economês", o Estado não seria eficiente. O Estado, pintado como um elefante ${ }^{3}$ (grande, pesado...) teria seu papel resumido em intervir somente quando o retorno social do investimento é maior do que retorno privado - o que reduziria a chance de investimento do capital privado (MAZZUCATO, 2011 , p. 38).

Contudo, os Estados Unidos são um exemplo ideal para demonstrar que o Estado é o maior investidor que uma economia pode ter. Por ter objetivos distintos, como expressado acima, - Estado não teme maiores riscos como o capital privado e assume se arriscar em empreitadas que podem -ou não- dar retorno. “Um Estado empreendedor não apenas 'reduz os riscos' do setor privado, como antevê o espaço de risco e opera corajosa e eficientemente dentro desse

3

Propaganda do Governo Collor (1990-1992) para promover as estatizações: https://youtu.be/H1wE5_qZ3HI

Revista Multiface | Belo Horizonte | v. 9, n. 1, p. 37-58, 2021 
espaço para fazer as coisas acontecerem." (MAZZUCATO, 201 1, p. 43). E, muitas das vezes, o retorno esperado é no longo prazo -e o setor privado não tem muita paciência em cultivar os lucros.

Estado pode se resumir, como querem os ortodoxos, a uma máquina burocrática que não se envolve na economia, exceto para corrigir as falhas de mercado ou -como em todos os países altamente desenvolvidos, principalmente nos $E^{4} A^{4}-$ o Estado pode ser uma instituição guia para investimentos do setor privado, ser empreendedor e iniciar novos projetos assim como criar mercados (MAZZUCATO, 2011). Nas próximas seções, ficará claro qual dos moldes estatais resultou em desenvolvimento e crescimento econômico.

\section{A LENDA}

Chang (2002) classifica como "lenda" a versão ortodoxa do desenvolvimento dos países mais desenvolvidos com ênfase no livre comércio e na política do laissez-faire. Especificamente quanto aos Estados Unidos, ressalta que, quando a supremacia industrial americana ficou patente, depois da Segunda Guerra Mundial, o país replicou a Grã-Bretanha do século XIX, "preconizando o livre comércio, muito embora tivessem obtido essa supremacia mediante o uso nacionalista e de um vigoroso protecionismo" (CHANG, 2002, p.18). E acrescenta que a

\footnotetext{
"suposta história de livre-comércio e mercado livre dessas nações é apresentada como exemplo aos países em desenvolvimento. No entanto, tais discussões sobre a experiência britânica e norte-americana são extremamente seletivas e, portanto, ilusórias" (CHANG, 2002, p.21)
}

Mesmo na era de ouro do liberalismo clássico, "virtualmente todos os países desenvolvidos usaram ativamente políticas industrial, comercial e tecnológica (ICT) intervencionistas para promover a indústria nascente durante o período de catch-up" (CHANG, 2002, p.35), em que a proteção tarifária não foi o único e nem o mais importante mecanismo

4 “O que se descobre é que, além de ser uma sociedade empreendedora, um lugar onde é culturalmente natural criar e expandir um negócio, os Estados Unidos são também um lugar onde o Estado desempenha um papel empreendedor, fazendo investimento em áreas radicalmente novas. O Estado forneceu o financiamento em estágios inicias onde capital de risco fugiu, ao mesmo tempo em que comissionou no setor privado uma atividade altamente inovadora que não teria acontecido sem políticas públicas com visão e estratégia definidas." (MAZZUCATO, 2011, p. 203)

42 Revista Multiface | Belo Horizonte | v. 9, n. 1, p. 37-58, 2021 
de proteção. Havia ainda subsídios, reembolsos alfandegários, investimentos públicos, incentivo à pesquisa e até a pirataria 5 .

Especificamente quanto aos Estados Unidos, Chang afirma que "é impossível subestimar a importância da proteção à indústria nascente no desenvolvimento do país" (CHANG, 2002, p.49). Proteção alfandegária e mesmo proibição de importações foram fonte de inspiração -e mais uma vez, influenciaram a política industrial do Leste Asiático no pós-guerra (CHANG, 2002, p.51). A guerra contra a Grã-Bretanha também forneceu uma "proteção natural" (CHANG, 2002, p.52). Outra guerra, a de Secessão (1861-1865), teve como pano de fundo a questão tarifária, ao lado da escravidão. A vitória foi do protecionismo.

Na Grande Depressão do século seguinte, seguiram-se variações sobre o mesmo tema. Liberalização, mesmo, com pregação de livre comércio, os EUA só praticaram depois da Segunda Guerra Mundial - ainda assim, em menor grau que a Grã-Bretanha. Mas nem só de protecionismo viveu o desenvolvimento americano. Incentivo a pesquisa, educação e subsídios também foram ingredientes importantes, ao lado do investimento em pesquisa e desenvolvimento, principalmente militar (CHANG, 2002).

Coronel, Azevedo e Campos (2014), também destacam que "apesar das controvérsias que cercam o uso de políticas industriais, elas foram utilizadas por várias nações, especialmente em países da Europa, Estados Unidos e países asiáticos" (CORONEL, AZEVEDO \& CAMPOS, 2014 , p.106). Depois da independência, os EUA concentraram o desenvolvimento "em duas regiões, a Sul, escravocrata, e a Norte, que se balizou no setor industrial e defendia proteção ao setor através de restrição voluntária às importações, imposição de cotas e tarifas e sanções" (CORONEL, AZEVEDO \& CAMPOS, 2014, p.107). O primeiro secretário do tesouro americano, Alexander Hamilton, foi um dos responsáveis pelas práticas protecionistas, segundo os autores, sob o argumento de que "a concorrência estrangeira e a força do hábito impediriam as novas indústrias que, em breve, poderiam ser competitivas internacionalmente, de se desenvolverem nos Estados Unidos, a menos que a ajuda governamental compensasse os prejuízos iniciais (CORONEL, AZEVEDO \& CAMPOS, 2014).

Dautt e Willcox (2017) também ressaltam o papel do secretário do tesouro e afirmam que, desde daqueles tempos, "o governo estadunidense tem papel substancial na política industrial, comercial e tecnológica. Os EUA sempre utilizaram um amplo espectro de políticas,

5 “É importante ressaltar que muitas dessas políticas são seriamente condenadas hoje em dia, ainda que os acordos bilaterais ou multilaterais não as tenham declarado explicitamente ilegais" (CHANG, 2002, p.37). 


\section{Neves \& Amaral}

sendo especialmente reconhecidos por seu apoio ao complexo industrial de defesa". $O$ desenvolvimento de uma infraestrutura institucional sempre esteve presente no estímulo do "desenvolvimento de inovações tecnológicas, conjugando o estímulo à pesquisa e desenvolvimento (P\&D) com diversas outras medidas, inclusive políticas comerciais, exigência de conteúdo local e compras públicas" (DAUTT e WILLCOX, 2017).

Da Costa (2017), em "Comparação entre o Desenvolvimento do Brasil e o dos Estados Unidos no Século XIX", também corrobora com tal ponto de vista, mas lembra que "o protecionismo surgiu nos EUA, como sistema geral de política econômica, em etapa já bem avançada do século XIX, quando as bases de sua economia já se haviam consolidado".

\section{O DESENVOLVIMENTO DA GRÃ BRETANHA}

Antes de tratar sobre a ascensão de uma economia retardatária, é preciso retornar à história de desenvolvimento da economia pioneira em termos de industrialização. Ou seja, é necessário falar sobre o processo pela qual a Grã-Bretanha passou. Um trabalho referência para abordar o processo de desenvolvimento por uma perspectiva histórica é o de Chang (2002) que analisa diferentes economias e seus processos de industrialização. De forma geral, o autor desconstrói o mito neoliberal do laissez-faire e a aposta em produção de bens de acordo com as vantagens comparativas de cada economia como estratégia para o desenvolvimento. Neste cenário mitológico, o Estado deve reduzir ao máximo sua atuação, sendo prudente ao extremo ao avaliar se deve ou não intervir diante de falhas de mercado, incorrendo no risco de agravá-las, ao invés de extingui-las. O autor, porém, não nega a existência de um eventual sistema de livre comércio. Ele pontua que este momento surge apenas quando convém à economia em processo de industrialização, que já atingiu certo patamar de liderança tecnológica.

Seu principal ponto de análise é a ativa participação do Estado neste desenvolvimento. No que tange à Grã-Bretanha, a monarquia inglesa, desde o século XIV, tinha a aspiração de desenvolver a indústria nascente que no caso se traduzia no setor têxtil. Henrique VII investiu em pesquisas e projetos para fomentar esse setor, como com a contratação de mão-de-obra especializada dos Países Baixos, o aumento de tarifas e a proibição temporária de exportação de lã bruta. O processo de acumulação de capital, fundamental para a industrialização, também teve base na colonização direta, escravatura capitalista e nacionalismo econômico (ARRIGHI, 1996, p. 49). 
Por se caracterizar como um processo de diversas etapas, somente quase cem anos depois do início da Substituição de Importações, a Grã-Bretanha pode se estabilizar no cenário internacional como indústria competitiva, a ponto de reunir condições e de fato efetivar a proibição completa da exportação de lã bruta. Toda essa estratégia, encabeçada pelo Estado, desmantelou os Países Baixos, potência do ramo até então. Porém, essas não foram as únicas medidas adotadas pelo estado inglês com vistas a acumular capital. Antes dessas medidas, o governo britânico controlava o comércio por meio da colonização, como com o Navigation Acts, que exigia que toda troca comercial com a Grã-Bretanha fosse feita com navios britânicos. Assim, para que a viagem compensasse, os navios britânicos deixavam o porto carregados com mercadorias nacionais e, ao chegar a seu destino, descarregava aquela mercadoria e carregava os bens a serem vendidos no mercado inglês. Por este sistema, era obrigatória a aquisição de bens britânicos, caso algum país tivesse intenções de adentrar com seus produtos no mercado da rainha.

Chang (2002) demonstra como o Estado britânico visou, no primeiro momento, acumular capital para então, a partir de 1721, investir no desenvolvimento da indústria manufatureira, objetivando importar matéria prima e exportar bens manufaturados; ação que foi declarada pelos parlamentares como essencial ao bem estar público. Em ato complementar, as colônias inglesas foram tolhidas de participarem do comércio internacional, a despeito da qualidade do produto (como o caso do algodão da Índia, de qualidade superior, e a lã na Irlanda). Com as restrições impostas, pouco mais de cem anos depois, a Grã-Bretanha dominou esses mercados, chegando até mesmo a exportar esses produtos para suas colônias - não sem antes impor restrições produtivas a elas.

Após esforços para cercear o comércio livre, para proteger a indústria nacional, o fim das Guerras Napoleônicas ascenderam nos detentores de manufaturas a gana de abertura comercial de forma mais inflamada, uma vez que já haviam se estabelecido como superiores e mais eficientes com relação ao resto do mundo, na maior parte dos empreendimentos. A revogação da Corn Law e o acordo anglo-francês de livre comércio foram marcos de abolição tarifária, sendo que, na década de 1850, o Estado britânico havia reduzido significantemente suas tarifas lançando os produtos ingleses no mundo com notória competitividade (CHANG, 2002). Mas, para este nível de abertura comercial ser possível, a Grã-Bretanha passou por um histórico de tarifas e restrições de exportação que foram essenciais para a construção e consolidação do império. Chang (2002) ressalta que o "status fronteiras abertas" foi observado atentamente pelo Estado, que estava pronto para intervir aos primeiros sinais de vacilo da 
estabilidade econômica em razão da abertura comercial. Vale ressaltar que esta abertura não foi trivial, demandando anos para se consolidar.

Ironicamente, os anos demandados para se instaurar o "livre comércio" não superaram os anos de seu esplendor: Na década de 1880, alguns fabricantes britânicos já exigiam proteção do governo, por estarem passando dificuldades (CHANG, 2002). No início do século XX, a Grã-Bretanha retornava para seus moldes protecionistas, em razão da sua perda de eficiência diante da produção estadunidense e alemã (CHANG, 2002). Finalmente, em 1932, a Grã-Bretanha, diante da sua vantagem tecnológica superada por outros países, retornou às tarifas de forma abrangente. Entretanto, já era tarde: os EUA já haviam superado a produção Britânica em termos de eficiência de tal maneira que não foi possível recuperar seu antigo status de superpotência hegemônica (CHANG, 2002).

\section{A LIDERANÇA DOS EUA}

Nelson e Wright (1992) destacam que a liderança dos EUA no início do pós-guerra não foi apenas um resultado temporário. A base desse domínio estava no acesso favorável a recursos naturais e ao maior mercado doméstico do mundo. Os investimentos privados e públicos em P\&D e a educação científica e técnica eram refletidos nas indústrias de alta tecnologia. Nelson e Wright (1992) exploram o conceito de "tecnologia nacional" (NELSON \& WRIGHT, 1992, p.1935), em que havia uma interação de engenheiros a gerentes e operadores de máquinas, bem como investimentos em instalações e equipamentos. Segundo os autores, esse avanço tecnológico envolveu a interação entre muitas pessoas e empresas. Um aprendeu com a invenção do outro e deu um passo adiante, processo a que chamam de "invenção coletiva", numa eficiente rede, em que uma comunidade tecnológica nativa era capaz de adaptar as técnicas europeias às condições americanas (NELSON \& WRIGHT, 1992).

O embalo vinha do século anterior, com a ascensão das oportunidades de produção e comercialização em massa oferecidas pelas redes ferroviárias e telegráficas nacionais. Já em 1900, a indústria siderúrgica americana havia se tornado líder mundial e o país estava exportando uma ampla gama de produtos de ferro e aço - sendo ainda impulsionada pela produção de carvão, minério de ferro, cobre, petróleo e praticamente todas as outras matériaprimas para as grandes indústrias daquela época (NELSON \& WRIGHT, 1992, p.1938). E, associada à tecnologia avançada, estava a força organizacional americana, com a administração científica e a gestão profissional. 
No início da Primeira Guerra Mundial, os EUA lideravam as indústrias de produção e distribuição em massa, uma tecnologia caracterizada por economias de escala, intensidade de capital, padronização e uso intensivo de recursos naturais. Junto a isso, corria o apoio público à pesquisa, com a participação de profissionais da química, inclusive dentro das indústrias e seus departamentos de P\&D. O setor elétrico também foi um destaque (NELSON \& WRIGHT, 1992). Segundo Nelson e Wright (1992), as indústrias dos EUA estavam isoladas territorialmente pelo oceano Atlântico dos problemas causados pela guerra. E o país já era altamente protecionista desde a Guerra Civil. Mais uma vez, o mercado interno, enorme, bastava. Os autores destacam que a indústria automobilística foi a história de sucesso americana mais espetacular do período entre guerras (NELSON \& WRIGHT, 1992, p.1944). A grande empresa automobilística veio como um pacote: organizacional, gerencial ${ }^{b}$, financeiro e tecnológico. Sem contar o acesso fácil e abundante a um importante e emergente recurso energético e matéria-prima: o petróleo. Também foram capitais os investimentos em educação e tecnologia, diretamente ligada aos ganhos de produtividade.

Nelson e Wright (1992) lembram que, assim como após a Primeira Guerra Mundial, os Estados Unidos saíram favoravelmente da Segunda Guerra Mundial, com capacidades tecnológicas estendidas pela experiência de produção em tempos de guerra, enquanto a Europa saiu arrasada. Os autores completam: os setores nos quais os EUA avançaram após a Segunda Guerra Mundial exigiam experiência, treinamento especializado e pesquisa e desenvolvimento organizados para o avanço efetivo da tecnologia. Os cientistas e engenheiros que se envolveram no esforço de guerra tiveram um sucesso notável no argumento de que a ciência universitária merecia apoio público e, durante a meia década após a guerra, o governo instalou mecanismos para isso (NELSON E WRIGHT, 1992, p.1951). Em meados da década de 1950, as universidades americanas de pesquisa estavam claramente à frente das do resto do mundo. O domínio americano em tecnologias de computador e semicondutores ganhou a maior atenção e preocupação dos europeus durante as décadas de 1950 e 1960.

A Carta do Instituto de Estudos para o Desenvolvimento Industrial (IEDI) de 2017 também ratifica os argumentos expostos acima, ao destacar o papel ativo do governo federal ao empreender "uma série de grandes esforços tecnológicos em estreita colaboração com a indústria, laboratórios da indústria e pesquisadores universitários" (IEDI, 2017, p.8).

6 Este modelo gerencial ao qual Nelson e Wright (1992) se referem é o fordismo. 


\section{NEW DEAL}

A política batizada como New Deal cristalizou duas correntes antagônicas de pensamento em um novo tipo de liberalismo. A afirmação é baseada no que expõe Almeida (1988), ao definir tais visões como a que se baseia em Adam Smith e a perda do individualismo auto-suficiente e a que vê no governo a responsabilidade pelo bem-estar da nação e o mercado com desconfiança, dotado de falhas que produzem consequências desastrosas, sendo o Estado "provido de onisciência e onipotência", com "a capacidade de curar esses males através da intervenção ativa no mercado" (ALMEIDA, 1988, p.44).

Já Kennedy (1999), apresenta o New Deal como um pacote de medidas implementadas pelo governo de Roosevelt, que acarretaram em mudanças expressivas na economia estadunidense. Tais medidas foram pensadas para assegurar um "capitalismo seguro", reduzindo as incertezas e os choques econômicos. Para o autor, os frutos do New Deal foram determinantes para o quarto de século mais próspero da economia estadunidense, que estava colhendo os frutos da era pós-guerra. E, ainda, o autor não deixa de enfatizar que, embora as reformas tenham se findado em 1938, o rol de transformações sociais e institucionais que ocorreram dentro dos cinco anos de Plano são praticamente incomparáveis com as ocorridas em outros períodos.

Embora o New Deal não tenha recuperado a economia, redistribuído a renda e extinguindo a propriedade privada (isto é, nenhuma estatização ocorreu ou empresa estatal de importância notória surgiu no período), ele caracterizou um período repleto de oportunidades. Uma das maiores características do Plano, e herança, é a ampla securitização: não se resumiu a um grupo seleto, mas se espalhou de capitalistas a empregados, de corporações a fazendas, enfim, todo o rol de seguros possíveis era contemplado pelo New Deal. Roosevelt, afirma Kennedy (1999, p. 365), vendeu a ideia de que o Estado era o principal mecanismo de securitização para os americanos -e, portanto, ele deveria crescer-e, de todas as áreas atingidas, o setor financeiro foi um dos primeiros e mais notórios.

Como pilares, o Plano seguia as seguintes premissas: i) A crença de que a era do crescimento econômico tinha acabado; ii) se o setor privado for deixado ao lév, ele jamais seria capaz de retornar aos níveis de investimento e emprego para, pelo menos, manter a produção equiparada aos anos 1920 e iii) os EUA eram uma economia autossuficiente. Pelo seu estudo, o autor conclui que a ideia do New Deal não era desconstruir o capitalismo, mas instaurar um sistema relativamente sem risco. Para isso, o objetivo era reduzir a volatilidade e compartilhar, 
de forma mais igualitária, os benefícios. Ficou estabelecido que a saúde da economia e bemestar dos cidadãos eram responsabilidade do Estado (KENNEDY, 1999, p. 377).

Diante do colapso dos bancos em 1933, Kennedy (1999) afirma que o New Deal estava entre estatizar o sistema bancário ou atender aos auspícios dos centros financeiros de relaxar as medidas para que, "naturalmente", surgisse um setor bancário privado altamente concentrado, com algumas poucas instituições poderosas para administrar o sistema. A opção adotada, porém, foi uma mudança estrutural totalmente diversa dessas opções: o Glass-Steagall Banking Act. Essa medida não só separou os bancos comerciais dos bancos de investimento, como também instaurou uma nova instituição, a Federal Bank Deposit Insurance Corporation). Dessa forma, seria evitado pânico nos sistemas bancários e falências aos montes, como as vistas antes, na Grande Depressão. O Glass-Stealgall Banking Act trouxe segurança para o mercado financeiro. Outro problema a ser resolvido pelo New Deal era o monopólio e manipulação da informação dos mercados. Como solução, foi instaurada a Securities Exchange Commission para regulamentar e fiscalizar essas práticas observadas em Wall Street (Kennedy, 1999, p. 367).

No que tange ao capital privado, o New Deal implementou medidas e criou órgãos para incentivar o setor imobiliário, provendo empréstimos e seguros para que a iniciativa privada pudesse se sentir motivada a atuar (KENNEDY, 1999). Neste aspecto, Kennedy (1999, p. 370) ressalta que a parceria público-privada foi fundamental para o bom funcionamento da política. Este resultado ecoou por cerca de quatro décadas depois, de tal forma que dois terços dos americanos moravam em casa própria e apenas $1 \%$ da população vivia em casas populares. Na agricultura, um setor com números voláteis na época, foi concedido subsídio para que os produtores deixassem de produzir, assim como foram aplicadas leis trabalhistas que proibiam o trabalho infantil e estabeleciam a aposentadoria compulsória aos 65 anos. Essas medidas foram tomadas para equilibrar a competição no setor agrícola e aumentar o número de vagas de emprego (KENNEDY, 1999).

Outras importantes medidas sociais foram o acolhimento da comunidade de imigrantes que havia se instalado nos EUA antes da década de 1930, a modernização da região rural, seguros previdenciário e desemprego, maior oferta de emprego destinado aos negros estadunidenses e proteção ao povo indígena (como construção de estradas, hospitais, pontes, aumento de terra, dentre outros). Indubitavelmente, o New Deal representou a instalação de um modelo de bem-estar social americanizado, confiando ao Estado a responsabilidade de assegurar à população uma economia segura, provendo também, outras assistências sociais (KENNEDY, 1999). 
A partir dessa exposição, fica notória a participação crucial do Estado para estruturar a economia e colocá-la nos moldes propícios para o seu florescimento. O New Deal surge em um contexto de crise para salvar a economia e a população estadunidense, não se preocupando apenas com as questões dos capitalistas, mas olhando também para as questões sociais. A reestruturação via mercado, visionada pelo setor privado, se mostrava inviável. Os ajustes feitos pela "invisível mão do mercado", assumindo que são efetivas, não são instantâneas, ao passo que se fazia urgente recobrar a sensação de segurança para os agentes do mercado e assistir a população com provisão de bens e serviços.

\section{PODER E TECNOLOGIA}

Segundo Almeida (1988, p.22), no pós-guerra, os EUA "passaram a dominar a pesquisa acadêmica de caráter fundamental, assim como os desenvolvimentos aplicados mais promissores nos campos eletrônico, mecânico e químico-farmacêutico". Em nível federal, o estado promoveu intervenções em várias áreas industriais, sendo que "os principais campos da intervenção pública em favor do setor industrial [passavam] pelo complexo industrial-militar" (ALMEIDA, 1988, p.19). Como consequência, prossegue Almeida(1988), os recursos públicos federais assumiram uma importância fundamental no financiamento de atividades inovativas em setores intensivos em tecnologia, destacando-se os setores de equipamentos de comunicações, componentes eletrônicos e no complexo aeronáutico, em que "a participação do governo federal é bastante superior à média do setor industrial".

O investimento na indústria armamentista, sob o pretexto de investimento em defesa, concentrou grandes esforços do Estado no desenvolvimento tecnológico e científico. Medeiros (2004) destaca que o comprometimento militar americano com a pesquisa científica já vinha da II Guerra Mundial e cita a criação do National Defense Research Council (NDRC), em 1941, que "estabeleceu uma nova estrutura para a ciência e engenharia criando uma ampla rede de pesquisas junto às universidades. Como resultado destes esforços, as inovações desenvolvidas nos laboratórios industriais criaram uma nova geração de armas e equipamentos." Dwight Eisenhower deu o nome de complexo industrial-militar, que era mais, segundo $\circ$ autor, um "complexo militar-industrial-acadêmico". A visão principal era de que "a pesquisa para fins militares seria melhor desenvolvida se os cientistas e engenheiros permanecessem com seu status civil em instituições acadêmicas e industriais. Isto é, as organizações acadêmicas e industriais trabalhariam em parceria com o governo federal, mas não sob seu controle direto" (MEDEIROS, 
2004). Segundo o autor, sob tal aspecto, as universidades constituíam o centro vital da pesquisa científica.

Kavanami (2018) define como "Capitalismo do Pentágono" a influência do Departamento de Defesa e de um novo tipo de gerenciamento que permitia um crescimento quase ilimitado para o setor de defesa. A autora ressalta que "a influência dos militares não ficaria restrita apenas à provisão de recursos para $P \& D$ e às compras de armamentos pelo governo, mas também se ocuparia da montagem de instituições voltadas para o deslocamento da fronteira científica e aceleração do processo tecnológico". E destaca tal processo como "a principal força autônoma na configuração e desenvolvimento do processo inventivo do país" (MEDEIROS, 2004, apud KAVANAMI, 2018, p.8). Nada mais revelador e apropriado, para a defesa dos argumentos do presente trabalho, que a expressão "Capitalismo do Pentágono", particularmente nessa área.

Mas, na década de 1960, a desaceleração do crescimento da produtividade nos EUA já havia começado. A própria OCDE argumentou que havia pouco conhecimento que os cientistas e engenheiros americanos dominassem que os europeus também já não soubessem (NELSON e WRIGHT, 1992, p.1954). De meados dos anos 1960 até meados dos anos 1980, a parcela de todas as patentes mundiais concedidas aos americanos foi relativamente constante. A participação do Japão é que aumentou dramaticamente, principalmente às custas da Europa (NELSON E WRIGHT, 1992, p.1955). Para os autores, o declínio nos custos de transporte e barreiras comerciais expandiu enormemente $\circ$ fluxo do comércio mundial, erodindo as vantagens em tamanho de mercado e custos de matéria-prima que tinham as empresas americanas. E a tecnologia tornou-se muito mais acessível para aqueles com as habilidades necessárias e dispostos a fazer os investimentos necessários. Os negócios se tornaram cada vez mais internacionais. Nelson e Wright(1992) acrescentam ainda o declínio na importância do transbordamento da P\&D militar para a tecnologia civil. Por fim, concluem que a convergência ocorreu entre as nações com sistemas educacionais modernos, fortes comunidades científicas e de engenharia internas, e empresas industriais sofisticadas. Nações sem esses atributos tenderam a ficar cada vez mais para trás.

\section{MAS NÃO FOI O ESTADO APENAS}

Os estudos aqui analisados destacam a importância capital do estado no processo de desenvolvimento note-americano. Mas é preciso também lançar um olhar para o cenário de forma um pouco mais abrangente e fazer, não uma espécie de contraponto, mas uma descrição 
complementar do panorama, dos elementos e das personagens envolvidos nesse processo. Uma fonte rica para ilustrar esse lado da história é a abordagem feita por Cury (2006) ao analisar - processo de industrialização (1850-1914) dos EUA pelas lentes de Alfred D. Chandler, enfatizando três importantes pilares para $\bigcirc$ desenvolvimento norte americano: $\bigcirc$ desenvolvimento de uma rede básica de comunicações e transportes, que permitiu o alargamento contínuo do mercado; processos de produção e distribuição em massa, sendo esta uma das características mais marcantes do capitalismo estadunidense; e o surgimento das corporações modernas, que é o resultado da integração dos métodos de produção e de distribuição em massa no interior de uma mesma empresa de negócios.

Em conformidade com esses pilares, o trabalho de Chandler (1977) coloca a empresa como o agente econômico principal, assim como protagonista das transformações operadas na estrutura de produção e distribuição (CURY, 2006, p. 96). Outros aspectos também são destacados pelo autor como importantes para entender o sucesso do desenvolvimento dos EUA como o vasto território, abundância de recursos naturais e "energia extraordinária do seu povo" e a contribuição imensa dos imigrantes. Estes fatores em conjunto e orquestrados pela "Mão visível" (título do livro de Chandler), concatenaram para inovação que surgiu entre 1880 e 1914 no solo americano: A fundação da grande empresa industrial moderna.

Às vésperas da Primeira Guerra Mundial, os EUA já haviam garantido seu lugar de grande potência, tendo ultrapassado seus concorrentes em vários segmentos como a produção de aço. As mudanças mais significativas ocorreram entre 1850 e 1914 e as empresas que surgiram posterior a essa data seguiram as mesmas matrizes organizacionais estabelecidas dentro destes cinquenta anos. O sucesso da expansão estadunidense no período é creditado à progressiva substituição da "mão invisível do mercado" pela "mão visível da administração coordenada" (CURY, 2006, p. 134-135).

Ao final desse processo, as principais indústrias estadunidenses eram dominadas por poucas firmas que rapidamente haviam se modificado em grandes empreendimentos verticalmente integrados e altamente centralizados (CURY, 2006, p. 97). Essas empresas, caracterizadas pelo seu grande porte, coordenação, administração por profissionais assalariados, substituíram as firmas familiares progressivamente. $O$ início dessas transformações e o surgimento desse, até então, novo modelo empresarial tem origem no desenvolvimentos das ferrovias.

Iniciada a partir de 1850, as inovações tecnológicas das ferrovias permitiram que as indústrias que estavam se enraizando no período aproveitassem das vantagens deste meio de 
transporte. Cury (2006) explica que os trilhos, além de proverem um acesso mais direto do que lagos e rios, não ficavam parados durante o inverno e contribuíram para o barateamento do frete de mercadorias. Essas contribuições tiveram papel fundamental para fazer das ferrovias pop (CURY, 2006).

Esse empreendimento também teve largo impacto na constituição econômica das instituições estadunidenses, pois foi o primeiro segmento da economia a desenvolver uma estrutura administrativa complexa com o intuito de aumentar a eficiência na coordenação das atividades (CURY, 2006, p. 101). As hierarquias administrativas são um exemplo de mudança vista nas instituições. Seu surgimento é devido ao considerável volume necessário para o empreendimento ferroviário, de tal maneira ser impossível um indivíduo ou até mesmo um grupo de sócios possuírem a quantia necessária. Dessa forma, não tardou para as empresas do setor ferroviário se tornarem de capital aberto. Disto, surgiu o impasse: quem iria administrar essas empresas de alta complexidade organizacional? A resposta viria a surgir em forma de uma nova categoria de trabalhadores: Os administradores profissionais. Conforme Chandler (1997 apud Cury, 2006), embora não fossem os proprietários do negócio, estes profissionais se esforçavam ao máximo no cumprimento de suas tarefas visando o sucesso da empresa e, por consequência, no seu próprio.

Foi nessa época que os mercados de capitais se tornaram mais sofisticados no país, pois as ferrovias exigiam financiamento externo para dar continuidade em suas operações. Também neste período que os bancos de investimento surgiram, se especializando nas vendas de "securities (ações, títulos de dívidas) das empresas ferroviárias norte-americanas a investidores europeus." (CURY, 2006, p.103)

Em conjunto com a inserção da hierarquia administrativa, a coordenação foi fundamental para a implantação do sistema ferroviário tal qual hoje os EUA conhecem. Ao final da década de 1860, o solo americano ainda não era completamente integrado pelos trilhos: vagões de uma empresa não conseguiam transitar sobre os trilhos de outra, gerando um alto custo de carregamento e recarregamento. "Para resolver esse tipo de problema, era necessário que as grandes empresas ferroviárias definissem práticas cooperativas, pelo menos em três pontos básicos: a conexão física das estradas, a criação de métodos operacionais, contábeis e organizacionais uniformes, e o uso de uma tecnologia padronizada." (CURY, 2006, p. 104-105)

Em razão das características do setor o mercado não conseguia absorver grande concorrência, havendo cada vez menos empresas grandes no ramo. "Diante desse quadro (...) só restavam às grande firmas duas alternativas: a concorrência por meio de preços ou o 
estabelecimento de algum tipo de acordo sobre os mesmos," (CURY, 2006, p.107-108), deixando notória a necessidade da "mão visível" da coordenação.

Acordos formais do tipo cartel foram feitos na época. Porém, a ausência de uma jurisdição que permitisse tais acordos decretou o fim desse tipo de associação. Com a Lei Antitruste de 1890, essas práticas passaram a ser ilegais, acabando de vez com qualquer possibilidade de sincronias dessa natureza. Após a lei Antitruste, a solução foi a fusão entre firmas (CURY, 2006).

A transformação vista no território norte americano permitiu o desenvolvimento na estrutura produtiva e distributiva na economia, sendo criado um sistema que hoje chamamos de produção e distribuição em massa. A velocidade do trânsito de informações, passageiros e cargas aliado ao crescimento do mercado estadunidense (crescimento da população e nível de renda durante a maior parte do século XIX) propiciaram para o surgimento das câmaras de comércio que operavam com produtos primários (CURY, 2006, p. 113). O surgimento de grandes empresas atacadistas foi algo revolucionário, os mercadores passaram a vender as mercadorias com o nome de suas firmas e não mais comissionados (CURY, 2006, 113).

Essas operações, na verdade, representaram a origem dos modernos mercados de futuros, cuja principal vantagem estava em permitir que $\circ$ transporte e a entrega das mercadorias fossem feitos no momento em que - produtor e o distribuidor estivessem prontos para efetuar a transação. Dessa forma, reduziam-se, de maneira significativa, os custos de crédito e de armazenamento. (CURY, 2006, p. 113)

Após os atacadistas, as empresas produtoras criaram suas próprias redes de distribuição e, assim, o produtor passava a ter contato direto com o cliente, sem necessitar de um intermediário. Outro sistema que logo ganhou espaço foi a atuação comercial por meio de entregas de encomendas pelo correio. Empresas como Sears, Roebuck \& Co. foram pioneiras no ramo e conseguiram aumentar sua renda de forma significativa, adotando esse modelo. Para coroar o sistema de distribuição estadunidense, surgiram as lojas de departamento e as grandes cadeias de lojas (CURY, 2006, p. 115).

O sistema produtivo, por sua vez, ganhou expansão devido a descobertas de minas de carvão na Pensilvânia no início dos anos 1830. A partir dessa descoberta, todas as outras indústrias dependentes desse insumo puderam se desenvolver com maior gás, sendo que "(...) as maiores possibilidades de aproveitamento das economias de escala estavam de fato nas 
indústrias que utilizavam os processos intensivos em energia, sendo tal característica determinante para a ampla adoção do sistema de produção em massa." (CURY, 2006, p. 118 ). Em meados de 1880, as indústrias mecânicas também puderam usufruir da produção em massa a partir da substituição da mão-de-obra manual para o maquinário e da integração de todo o processo produtivo, tornando-o contínuo.

Nas indústrias intensivas em capital, os altos custos fixos intensificaram a necessidade de uma verticalização para trás, com fins de controlar os insumos para a produção, assim como uma verticalização para frente -construção de redes de distribuição como já mencionado anteriormente. Portanto, a implementação da produção contínua, a verticalização para frente e para trás e fusão entre firmas compuseram o cenário para a produção e distribuição em massa tão característica da economia estadunidense. Essa estrutura adquirida pelas corporações dos EUA foi, em partes, o que fez com que essa economia se expandisse (CURY, 2006, p. 134).

\section{CONSIDERAÇÕES FINAIS}

O presente estudo, em forma de uma breve revisão bibliográfica, permite perceber que não houve progresso econômico e social, tanto nos EUA quanto na Grã-Bretanha, puramente devido ao sistema de laissez-faire. A promoção do livre comércio deve ser vista com olhar crítico, perguntando "cui bono?"7 sempre que o fogo do liberalismo econômico ganhar corpo. Afinal esse sistema só foi implementado ${ }^{8}$ quando a nação hegemônica da vez havia conquistado sua supremacia (Grã-Bretanha e EUA). As demais economias desenvolvidas, embora não tivessem capacidade de impor ao sistema internacional seu modelo de comércio, escolhiam o momento ideal para se voltar para seu mercado doméstico -e desenvolver e proteger a indústria nascente- e quando abrir suas fronteiras para a "livre" circulação de bens e serviços.

A perspectiva de Chandler, que destoa das demais apresentadas neste trabalho, trata o desenvolvimento da firma moderna como importante fator para os avanços econômicos estadunidenses. Ainda dentro de tal visão, é possível compreender que nem mesmo uma perspectiva voltada para a empresa, para o setor privado, está imune da intervenção. Isto é, as próprias empresas compreendiam que, deixadas aos cuidados das mãos invisíveis do mercado, elas não sobreviveriam. Foi necessária uma coordenação ímpar para que pudessem

\footnotetext{
7 "A quem interessa?"

8 Implementado, como forma de se dizer, pois “(...) os EUA nunca chegaram a ser tão liberais como a Grã-Bretanha” (CHANG, 2003 apud ZAGATO, 2017, p.19). E, quanto a Grã Bretanha "Adotou-se um modelo gradualista, em que o governo aumentava as tarifas conforme a indústria se expandia e, com ela, a demanda por lã. O contrário também foi colocado em prática, isso é, em momentos de alta oferta de lã, baixava-se temporariamente as tarifas." (IBDEM)
} 
se perpetuar e, somente assim, avanços em gestão e produção puderam se desenvolver acarretando em crescimento e distribuição da renda.

Voltando a Chang, comparadas as políticas de investimento em ciência e tecnologia dos países que se desenvolveram anteriormente às dos mais atuais, as mais recentes são muito menos protecionistas que as do passado, "tomando em conta a defasagem de produtividade que eles devem superar" (CHANG, 2002, p.106). E ainda pode-se concluir que "há um padrão histórico extraordinariamente persistente, que se estende da Grã-Bretanha do século XVIII à Coréia do fim do século $X X$, pelo qual se chegou ao desenvolvimento econômico bem-sucedido por meio de medidas de proteção à indústria nascente" (CHANG, 2002, p. 115) -que seria forte demais para se considerar obra do acaso.

Com isto, pode se estender as premissas de desenvolvimento dos Estados Unidos (e da Grã-Bretanha) para os demais países: dificilmente há desenvolvimento sem Estado, sem proteção à indústria nascente, sem coordenação entre os setores no mercado doméstico e, principalmente, não há desenvolvimento à mercê das mãos invisíveis do mercado. Abrir o mercado de um país pobre ou em desenvolvimento com vistas ao crescimento econômico apenas fará com que o país em questão aprofunde suas deficiências. Pois, adotando uma lógica liberal, a indústria doméstica não seria capaz de competir de forma pareada com as indústrias dos países desenvolvidos.

Isto é, no caso do país possuir uma indústria. Assim, progressivamente, suas estruturas internas seriam desmanteladas até se resumirem a serviços e produtos primários para suprir as economias mais complexas. E a competição, que seria o motor para mais investimentos e pesquisas, não passaria de "uma boa intenção", quando é precário o capital para por a cabo tais investimentos e pesquisas. Esse processo iria obrigar as economias menos desenvolvidas a se especializarem na produção e beneficiamento de bens menos complexos e com mais ubiquidade que refletem, de forma geral, menor valor e menor tecnologia. Para desenvolver uma indústria, como já colocado, é necessário investimento, capital. E é muito difícil -ou praticamente impossível, como nos diz a história- acumular capital produzindo potatoes chips e não, computer chips.

\section{REFERÊNCIAS}

ALMEIDA, I.C. de S. The "Chicago Boys" Intellectual Transfer: a Gramscian Interpretation. Economia Ensaios, Uberlândia, 34(2), Jan./Jun. 2020. 
ALMEIDA, Julio Sérgio Gomes de. Políticas industriais em países selecionados. Instituto de Estudos para o Desenvolvimento Industrial (IEDI). Out. 1998. Disponível em: https://web.bndes.gov.br/bib/ispui/bitstream/1408/18182/1/FCEst1 16440 Pol\%C3\%ADti cas $\% 20$ Industriais $\% 20$ em $\% 20 \mathrm{~Pa} \% \mathrm{C} 3 \%$ ADses $\% 20$ Selecionados compl P.pdf

ARRIGHI, G. O Longo Século XX: Dinheiro, poder e as origens de nosso tempo. $1^{\mathrm{a}}$ ed. Rio de Janeiro: Contraponto, 1996.

CHANG, Ha-Joon. Chutando a escada: a estratégia do desenvolvimento em perspectiva histórica. São Paulo: UNESP, 2002, cap. 2.

CORONEL, D. A.; AZEVEDO A. F. Z. de; CAMPOS, A. C. (2014). Política industrial e desenvolvimento econômico: a reatulização de um debate histórico. Brazilian Journal of Political Economy, 34(1), 103-119.

CURY, V. M. História da Industrialização no século XIX. Rio de Janeiro: Editora UFRJ, 2006.

DAUTT, Gabriel; WILLCOX, Luiz Daniel. Reflexões críticas a partir das experiências dos Estados Unidos e da Alemanha em manufatura avançada. BNDES Setorial, $n^{\circ} 44,2017$. Extraído de: https://www.bndes.gov.br/wps/portal/site/home/conhecimento/noticias/noticia/politicaindustrial-eua

HARVEY, D. O Neoliberalismo: História e implicações. São Paulo: Ediçõse Loyola, 2008.

IEDI. Indústria 4.0: O Plano Estratégico da Manufatura Avançada nos EUA. Carta IEDI, edição 820, 11 de dez. De 2017. Disponível em: https://iedi.org.br/cartas/carta iedi n 820.html

KAVANAMI, Vitória Moreira. (2018). O complexo industrial-militar-acadêmico e a inovação tecnológica nos Estados Unidos: elementos para manutenção da hegemonia. Disponível em: https://repositorio.ufu.br/bitstream/123456789/22014/3/ComplexolndustrialMilitar.pdf

MAZZUCATO, M. O Estado Empreendendor: Desmascarando o mito do setor público vs. setor privado. São Paulo: Portfolio-Penguin, 2014. 
MEDEIROS, Carlos Aguiar de. O desenvolvimento tecnológico americano no pós-guerra como um empreendimento militar. O poder americano. Petrópolis: Vozes, p. 225-252, 2004.

NELSON, Richard R.; WRIGHT, Gavin. The rise and fall of American technological leadership: the postwar era in historical perspective. Journal of Economic Literature, v. 30, n. 4, 1992.

ZAGATO, Lígia Maria de Jesus Cestari. A equalização das condições de competição como estratégia de catching up dos países industrializados em desenvolvimento no século XXI. 2017. Tese de Doutorado.

Artigo submetido em novembro de 2020 e aprovado em abril de 2021. 